\title{
Effectiveness of Protective Gloves against Engineered Nanoparticles: Difficulties in Evaluation
}

\author{
Ludwig Vinches*1, Mohamed Zemzem¹, Stéphane Hallé1, Caroline Peyrot ${ }^{2}$, \\ Kevin J. Wilkinson ${ }^{2}$, Nathalie Tufenkji ${ }^{3}$ \\ 1Dept of Mechanical Engineering, École de technologie supérieure \\ 1100 Notre-Dame West, Montreal (QC) H3C 1K3 Canada \\ ludwig.vinches@gmail.com,mouuuhamed2@gmail.com,stephane.halle@etsmtl.ca \\ 2 Dept. of Chemistry, Université de Montréal \\ C.P. 6128, succ. Centre-ville, Montreal (QC) H3C 3J7 Canada \\ caroline.peyrot@umontreal.ca,kj.wilkinson@umontreal.ca \\ ${ }^{3}$ Dept. of Chemical Engineering, McGill University \\ 3610 University St., Montreal (QC) H3A 0C5 Canada \\ nathalie.tufenkji@mcgill.ca
}

\begin{abstract}
Gold nanoparticles ( $\mathrm{nAu}$ ) are presently of great interest in research and industrial applications, because they can be easily and quickly synthesised and are chemically stable. A growing number of workers must handle these nanoparticles even though recent studies underline the potential health risks associated with their use. The current means of protecting the skin of the hands is limited to the use of disposable protective gloves, according to the recommendations of Health and Safety agencies. Recent research conducted by the authors has shown the poor effectiveness of nitrile rubber gloves against titanium dioxide nanoparticles in water. However, the evaluation of the effectiveness of protective gloves is difficult owing to some intrinsic parameters of the gloves' material composition and the nanoparticles. This study emphasizes the difficulties encountered when assessing the effectiveness of nitrile protective gloves against gold nanoparticles. One model of nitrile rubber gloves (thickness $~ 100 \mu \mathrm{m}$ ) and two sizes of spherical gold nanoparticles (5 and $50 \mathrm{~nm}$ ) in aqueous suspension were examined. To simulate the conditions of occupational use, glove samples in contact with $n A u$ suspensions were subjected to repeated mechanical deformations. It was shown that depending on the size of the nanoparticles, the results obtained by Inductively Coupled Plasma - Mass Spectrometry are different. For nAu-5, passage across the glove material is observed, but not with nAu-50. Surprisingly, with a different batch of the same gloves, no penetration is measured for $n A u-5$. Mechanical characterization of the glove materials; namely, strain energy and swelling tests, were performed in an effort to better understand the observed behavior. These external parameters can influence the penetration of nanoparticles through protective gloves. Indeed, mechanical deformations and
\end{abstract}

swelling induce a loss of the physical integrity of the glove sample.

Keywords: Gold nanoparticles, occupational use, protective gloves, strain energy, swelling.

(C) Copyright 2016 Authors - This is an Open Access article published under the Creative Commons Attribution License terms (http://creativecommons.org/licenses/by/3.0). Unrestricted use, distribution, and reproduction in any medium are permitted, provided the original work is properly cited.

\section{Introduction}

Gold nanoparticles are used for several purposes in the biomedical sector (Tiwari, Vig et al. 2011, Dykman and Khlebtsov 2012) or for optical, chemical or electronical applications (Guo and Wang 2007, Balasubramanian, Yang et al. 2010, Zhao, Li et al. 2013, Lokesh, Shambhulinga et al. 2015). However, several studies have reported the toxicity of bare or functionalized gold nanoparticles (Goodman, McCusker et al. 2004, Alkilany and Murphy 2010, Das, Debnath et al. 2012). For example, two independent research teams demonstrated the effect of gold nanoparticles on the spermatogenesis of humans and mice (Wiwanitkit, Sereemaspun et al. 2009, Zakhidov, Pavlyuchenkova et al. 2012). Wiwanitkit et al. showed that when human semen is placed in contact with a suspension of gold nanoparticles, $25 \%$ of the sperm becomes immobile and the gold nanoparticles penetrate the head and flagellum. A recent study by Fede (2014) evaluated the 
toxicity of gold nanoparticles to human endothelial cells in both static and dynamic flow conditions of exposure (Fede, Fortunati et al. 2015). They confirmed that at comparable concentrations, in static conditions the toxicity of nanoparticles is higher.

Sonavane et al. observed the penetration of gold nanoparticles (15 nm, $102 \mathrm{~nm}$ and $198 \mathrm{~nm})$ through rat skin. They concluded that the permeability coefficient and diffusion coefficient decrease as the nanoparticle size increases. They also measured a lag time (release of nanoparticles on the opposite face) of 3 to 6 hours only for particles with a diameter of $102 \mathrm{~nm}$ and $198 \mathrm{~nm}$, respectively. Other studies have proven the penetration of different nanoparticles through the skin: gold (Graf, Nordmeyer et al. 2015), titanium dioxide (Sadrieh, Wokovich et al. 2010, Vogt, Rancan et al. 2014), quantum dots (Ryman-Rasmussen, Riviere et al. 2006), fullerene (Rouse, Yang et al. 2007), zinc oxide (Gulson, McCall et al. 2010), silver (Vogt, Rancan et al. 2014, Zhu, Choe et al. 2014) and silicon dioxide (Vogt, Rancan et al. 2014).

Only few research groups have worked on the effectiveness of disposable protective gloves against nanoparticles; and most have focused on nanoaerosols. Golanski et al. performed tests on nitrile rubber, latex, neoprene and vinyl in contact with graphite nanoaerosols between 30 to $80 \mathrm{~nm}$ in size (Golanski, Guiot et al. 2008). Only diffusion coefficients were measured for the nanoparticles of $80 \mathrm{~nm}$ in diameter. In another study, the same researchers concluded the nonpenetration of graphite nanoaerosols $(40 \mathrm{~nm})$ through the same types of gloves and under the same experimental conditions (Golanski, Guiot et al. 2009). Park et al. studied the passage of silver nanoaerosols through nitrile rubber and latex gloves using Golanski's experimental setup (Park, Kwak et al. 2011) and concluded non-penetration for both models of gloves. Recently, Vinches et al. measured a significant penetration of $\mathrm{TiO}_{2}$ nanoparticles suspended in water through nitrile rubber and latex gloves under conditions simulating occupational use (i.e., using mechanical deformations) (Vinches, Dolez et al. 2013, Vinches, Peyrot et al. 2014).

The objectives of the present work are to: 1) determine the effectiveness of nitrile rubber gloves against gold nanoparticles in suspension and highlight the difficulties in their evaluation, and 2) study certain external parameters to attempt to explain the difficulties encountered.

\section{Materials}

\subsection{Protective Gloves}

The model of disposable $100 \%$ nitrile rubber glove selected for this study (Nitri-care $\AA 3005 \mathrm{PF}$ ) is from Showa Best Glove. It is one of the most commonly used safety gloves in the industry and in laboratories. It is made of latex, is powder-free and does not contain silica. For this study, the glove samples are taken from two boxes belonging to separate production batches. To simplify the notation, the gloves from the first batch are identified as NBR-1 and those from the second batch, NBR-2. The average thickness of this type of glove is $99.4 \pm 3.5 \mu \mathrm{m}$. All the samples used for penetration or swelling tests are cut from the palm or back section of the gloves.

\subsection{Nanoparticle Suspensions, Filtrates and Physiological Solution}

Gold nanoparticle suspensions were purchased from Nanocomposix (NanoXact grade, San Diego, CA). The first suspension is $50 \mathrm{~nm}$ gold particles (nAu-50) and the second $5 \mathrm{~nm}$ gold particles (nAu-5). Both suspensions are in MilliQ water and the gold nanoparticles are coated with polyvinylpyrrolidone. The gold concentration in the suspensions is 0.05 $\mathrm{mg} / \mathrm{mL}$. For all the tests, commercial suspensions are used directly without any dilution. The stability is guaranteed by the supplier for 6 months and both suspensions are stored at $4^{\circ} \mathrm{C}$ away from light.

To determine the nanoparticle effect of colloidal gold suspensions on the swelling phenomenon, nAu-5 and nAu-50 suspensions are filtered by ultrafiltration (Amicon Ultra-4, 3kDa, Millipore) to separate the nanoparticles from the carrier liquid.

A physiological solution employed as sampling solution is composed of $0.5 \%(\mathrm{w} / \mathrm{w})$ sodium chloride, $0.1 \%(\mathrm{w} / \mathrm{w})$ lactic acid and $0.1 \%(\mathrm{w} / \mathrm{w})$ urea (E.C.F. 1998). The $\mathrm{pH}$ of the solution is adjusted to 6 using a $1 \%$ ammonia solution.

\section{Methods}

\subsection{Characterization of Gold Suspensions}

Particle hydrodynamic diameters are measured by dynamic light scattering (DLS) (Mobius-Wyatt). To obtain statistically significant data, triplicate measurements are performed for each suspension. Moreover, for each type of particle, more than 100 
particles are imaged by TEM (Hitachi JEM-2100F) to obtain the size distribution of the $\mathrm{nAu}$.

\subsection{Experimental Setup and Sampling Protocol}

For this study, the experimental setup employed is the same reported by Vinches et al. (Vinches, Peyrot et al. 2014). A glove sample is placed between an exposure chamber (containing nAu suspensions) and a sampling chamber (containing a physiological solution as sampling solution). The setup allows for a mechanical deformation (MD) of the sample when its outer surface is in contact with nAu suspensions. Before each test, the sampling chamber is rigorously cleaned to minimize the risk of contamination (ultrasonic bath in $2 \%$ nitric acid for 20 minutes and ultrasonic bath in MilliQ water for 10 minutes). The time profile of MDs is a $50 \%$ deformation every ten seconds for a total period of 3 hours $(620$ MDs). More details about the experimental protocol can be found in (Vinches, De Santa Barbara et al. 2013, Vinches, Peyrot et al. 2014). To obtain statistically significant data, triplicate measurements are performed for all analyses.

Before each penetration test, a control sample is produced by rinsing the sampling chamber with the sampling solution. The nAu concentration is analysed by inductively coupled plasma mass spectrometry (ICPMS), (PerkinElmer NexION 300X) after acidic digestion with nitric acid. To reduce the sodium chloride concentration, all samples were diluted 10 times in MilliQ water.

\subsection{Strain Energy}

For each MD, the stress-strain curve is plotted to illustrate the variation in strain energy. An estimation of the relative strain energy is carried out by computing the area under the curve using the trapezoid method and Matlab software. More details about strain energy evaluation can be found in (Vinches, De Santa Barbara et al. 2013).

\subsection{Swelling Tests and Diffusion Coefficients}

Swelling can be quantified by measuring the glove sample length change as a function of time (Perron, Desnoyers et al. 2002, Vinches, Boulebnane et al. 2012, Vinches, Perron et al. 2012). Length gain measurements are performed on rectangular samples $(10 \mathrm{~mm} \times$ $60 \mathrm{~mm}$ ). To obtain statistically significant data, three replicate samples are tested. Samples are immersed in $\mathrm{nAu}$ suspensions, filtrates or MilliQ water corresponding to the liquid carrier of the gold nanoparticles. At regular intervals, samples are removed from the liquid and measured using a Vernier caliper $( \pm 0.01 \mathrm{~mm})$. The length change ratio is defined as:

$\Delta L(t)=\frac{L_{t}-L_{0}}{L_{0}}$

with $\mathrm{L}_{\mathrm{t}}$ being the length at a given time and $\mathrm{L}_{0}$ the corresponding reference value. For all swelling tests, triplicate measurements are performed to obtain statistically significant data.

With the length change data, it is also possible to estimate the diffusion coefficients through the glove sample for each solution. Based on Fick's second law, the ratio between the length at time $t\left(L_{t}\right)$ and infinite time ( $\mathrm{L}_{\infty}$, i.e. maximum swelling) is equal to 0.5 at halflife time $\left(t_{1 / 2}\right)$ (Vinches, Perron et al. 2012):

$\frac{L_{t}-L_{0}}{L_{\infty}-L_{0}} \cong 1-\frac{8}{\pi^{2}}\left\{\exp \left(-D \frac{\pi^{2}}{e^{2}} t_{1 / 2}\right)\right\}=0.5$

where D is the diffusion coefficient $\left(\mathrm{m}^{2} \cdot \mathrm{s}^{-1}\right)$ and e, the thickness of the sample.

The value of $t_{1 / 2}$ can be determined from the linear regression of $\left(L_{t}-L_{0}\right) /\left(L_{\infty}-L_{0}\right)$ as a function of the square root of time for a value of $\left(L_{t}-L_{0}\right) /\left(L_{\infty}-L_{0}\right)=0.5$. The diffusion coefficient can be estimated from (Vinches, Perron et al. 2012):

$\mathrm{D} \cong \frac{0.04919 \times \mathrm{e}^{2}}{\mathrm{t}_{1 / 2}}$

\section{Results and Discussion}

\subsection{Characterization of Gold Nanoparticle Suspensions}

The hydrodynamic diameters measured by DLS are $(9.2 \pm 0.2) \mathrm{nm}$ and $(67.2 \pm 0.6) \mathrm{nm}$ for $\mathrm{nAu}-5$ and $\mathrm{nAu}-$ 50 , respectively. The size distributions of the nAu-5 and $\mathrm{nAu}-50$ are determined by analysis of TEM images. The mean particle sizes obtained are $(5.0 \pm 0.6) \mathrm{nm}$ and $(47.9 \pm 4.7) \mathrm{nm}$ respectively. These results confirmed the manufacturer's data. 


\subsection{Penetration of $n A u$ : ICP-MS Results}

The first results are obtained with NBR-1. Firstly, to ensure that the concentrations of gold measured are a result of the passage of nanoparticles through the glove sample, control tests were carried with no nanoparticles. All the gold concentrations are under the limit of detection of the ICP-MS (LOD: $0.048 \mu \mathrm{g} / \mathrm{L}$ ).

For penetration experiments conducted with nAu5, two replicates out of three showed significant concentrations of gold in the sample solution (7.158 $\mu \mathrm{g} / \mathrm{L}$ and $6.424 \mu \mathrm{g} / \mathrm{L})$ after 620 mechanical deformations (3 hours of deformations). This time corresponds to the estimated mean duration of wearing disposable gloves in the workplace. The gold concentration measured with the third test is below the LOD. This passage, measured in two samples out of three is possibly due to microcracks in the structure of the glove material. Although these values are low, NBR1 cannot be considered as totally effective against $5 \mathrm{~nm}$ gold nanoparticles under occupational use.

In experiments conducted with nAu-50, no penetration of nanoparticles is detected in the sampling solutions (LOD: $0.019 \mu \mathrm{g} / \mathrm{L}$ ). These results indicate a possible relationship between nanoparticle size and extent of penetration through nitrile protective gloves.

The same tests were conducted with the NBR-2 gloves and both gold colloidal suspensions. In both cases, in spite of triplicate measurements, no penetration of nanoparticles was detected (LOD $<0.037$ $\mu \mathrm{g} / \mathrm{L}$ for $\mathrm{nAu}-50$ and $\mathrm{LOD}<0.027 \mu \mathrm{g} / \mathrm{L}$ for $\mathrm{nAu}-5$ ). These contradictory results compared to those obtained using NBR-1 may be linked to variability in the manufacturing process of the nitrile protective gloves.

To attempt to explain the variable performance of the nitrile gloves in the nanoparticle penetration tests, two mechanical phenomena were investigated, namely the variation of the strain energy and the swelling of nitrile rubber.

\subsection{Strain energy}

The mechanical behaviour of the glove materials in presence or absence of gold colloidal suspensions was evaluated by measuring the strain energy for each deformation. When the sample is not exposed to $\mathrm{nAu}$ suspensions, a significant decrease in the strain energy is observed for the first hundred deformations reaching a relative drop of $36 \%$ (Fig. 2). The Mullins effect explains these results at least for the first ten deformations (Vinches, De Santa Barbara et al. 2013). During the initial deformation, some of the polymer chains reach their limit of extensibility and break, which leads to a reduction in the energy required for the same stress (Bueche 1960). Between 10 and 100 MDs, the strain energy continues to decrease. This is possibly due to a loss of surface integrity by abrasion, which gradually decreases the thickness of the sample. Additional tests are needed to confirm this hypothesis. Finally, after 100 MDs, the relative strain energy increases linearly with the number of deformations applied. This result suggests a stiffening of the sample probably due to a crystallization phenomenon, which hold sway over the abrasion of the material (Marchal 2006). An increase of the crystallinity rate causes a loss of mechanical integrity, which could facilitate the passage of the nanoparticles through the nitrile glove samples (Vinches, De Santa Barbara et al. 2013).

Figure 1 compares the variations of the NBR-1 material strain energy when exposed to either of the two gold suspensions. In these cases, there is no minimum observed in the curves and the relative strain energies measured decrease regardless of the number of MDs. In contact with the nanoparticle suspensions, the sample starts to swell (see section 4.4.). Gradually, polymer chains separate and release additives such as fillers, which lead to a weakening of the sample. Due to the loss of fillers and the increased spacing of the polymer chains, the phenomenon of crystallization under constraint seems to disappear completely. According to the standard deviations $(3 \%$ and $3.7 \%$ for $n A u-5$ and $\mathrm{nAu}-50$ respectively), this behaviour is independent of the NP size.

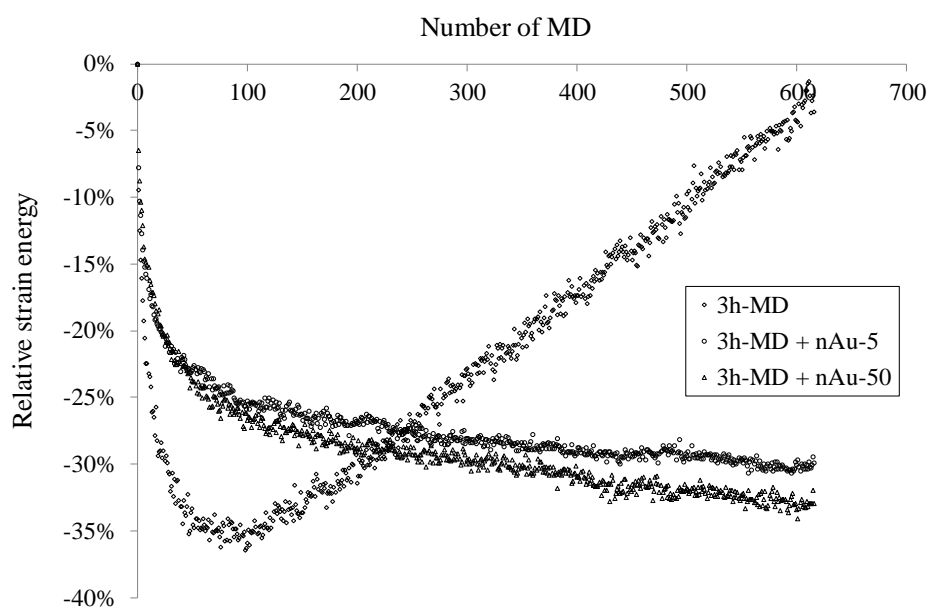

Figure 1. Relative strain energy for NBR-1 in the presence and absence of nAu suspension. 


\subsection{Swelling Tests and Diffusion Coefficients}

The first tests are performed with NBR-1 immersed in a nAu-50 suspension (solid line in Figure $2)$. A gradual increase in length is observed, until a plateau is reached $(14.5 \pm 0.7) \%$ after 110 hours of immersion. This plateau indicates that maximum swelling has been attained. For nAu-5, the swelling reaches $(14.1 \pm 0.1) \%$ after the same immersion time. It is of interest to determine the length change ratio after 3 hours which corresponds to the penetration test duration. For $n A u-5$, the length change ratio is $(3.7 \pm 0.3)$ $\%$ and for nAu-50, (3.8 \pm 0.2$) \%$. At first glance, these values seem low, but they are significant and can affect the degree of nanoparticle penetration through nitrile rubber gloves.

To evaluate the effect of the nanoparticles, swelling tests are also performed in filtered solutions (gold colloidal suspension without particles). The result obtained when the NBR-1 sample is immersed in the nAu-50 filtrate is shown in Figure 2. Although the length change ratio overlaps until 40 hours of immersion, a significant difference can be seen beyond this period. The value at the plateau is $(11.6 \pm 0.8) \%$. On the other hand, there is no significant difference in maximum swelling between the nAu-5 filtrate $(14.3 \pm 0.4) \%$ and nAu-5 suspension $(14.1 \pm 0.1) \%$.

The swelling data are compiled to determine the diffusion coefficients $(D)$ of gold suspensions and their filtrates. Figure 3 compares the diffusion coefficients of the gold colloidal suspensions and their corresponding filtrates (F/nAu-5 and $\mathrm{F} / \mathrm{nAu}-50)$ with NBR-1. Firstly, the diffusion coefficients obtained are low $\left(10^{-15} \mathrm{~m}^{2} / \mathrm{s}\right)$, whereas for organic solvents such as acetone, diffusion coefficients are on the order of $10^{-9} \mathrm{~m}^{2} / \mathrm{s}$ (Perron, Desnoyers et al. 2002). $D$ are comparable for both suspensions, which diffuse through NBR-1 in the same manner $\left(3.4 \times 10^{-15} \mathrm{~m}^{2} / \mathrm{s}\right)$. Secondly, the diffusion coefficients of the corresponding filtered solutions are systematically higher. It is possible that the nanoparticles act as a barrier thereby reducing the diffusion of the liquid carrier through the nitrile rubber sample.

Moreover, the diffusion coefficients are different between both filtrates $(5.6 \pm 0.3) \times 10^{-15} \mathrm{~m}^{2} / \mathrm{s}$ and $(8.9 \pm 0.4) \times 10^{-15} \mathrm{~m}^{2} / \mathrm{s}$ for $\mathrm{F} / \mathrm{nAu}-50$ and $\mathrm{F} / \mathrm{nAu}-5$ respectively. These results are likely due to the difference in chemical compositions of the liquid carriers (namely, the additives used as stabilizers). To validate this hypothesis, FT-IR analysis (Fourier Transform Infrared Spectroscopy) of the colloidal suspensions and filtered solutions should be performed (see Future work section).

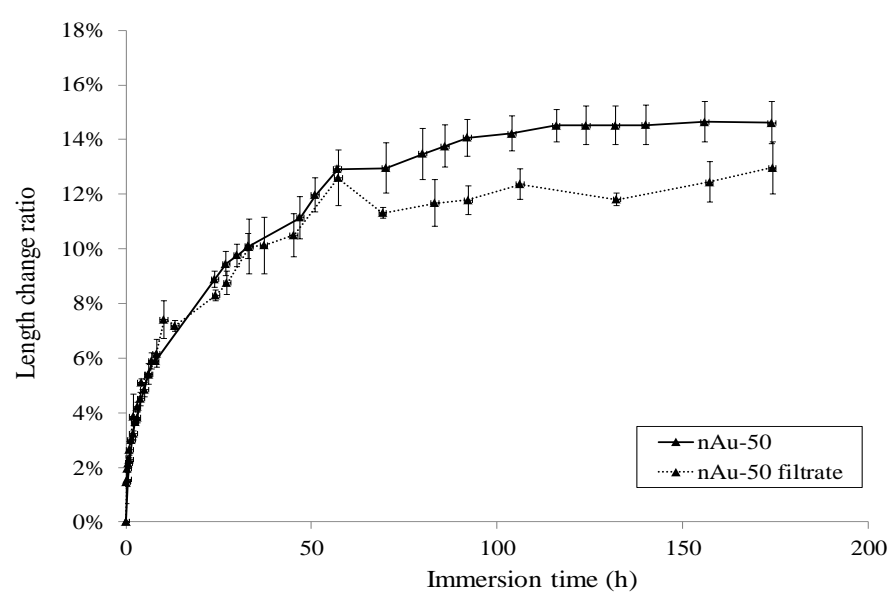

Figure 2. Comparison in length change ratio for NBR-1 in $\mathrm{nAu}-50$ suspension and in nAu-50 filtrate.

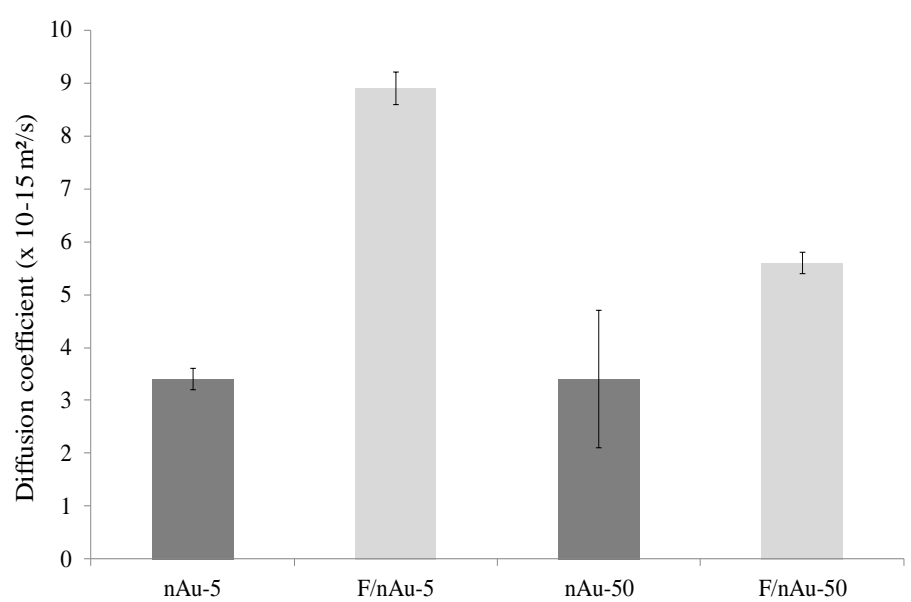

Figure 3. Diffusion coefficients for both nAu solutions and their filtrates.

As reported in section 4.2 , the penetration tests yield different results depending on the batch of nitrile gloves tested. To verify the variability in structure or chemical composition of the nitrile protective gloves, swelling tests were performed with NBR-2 in MilliQ water. The results are shown in Figure 4. During the 10 first hours of immersion, the two curves overlap and after 150 hours, NBR-1 and NBR-2 reach the same plateau near $13.6 \%$. However, between these times, the behaviour is completely different. NBR-2 achieves a maximum in length change $(18.8 \%$ after 75 hours of immersion) and decreases gradually to a plateau. These results could be attributed to the shrinkage of a larger number of chains during the swelling, which leads to a greater removal of fillers. Following these conclusions, 
Energy-dispersive X-ray spectroscopy analysis (EDX) was performed to determine the chemical composition of the inner and outer surfaces of the gloves. Depending on the batch of nitrile gloves, the results present significant differences in terms of silica, calcium, zinc, chloride and sodium (fillers) mass fractions. Thus, poor stability in the chemical composition of the nitrile gloves is confirmed.

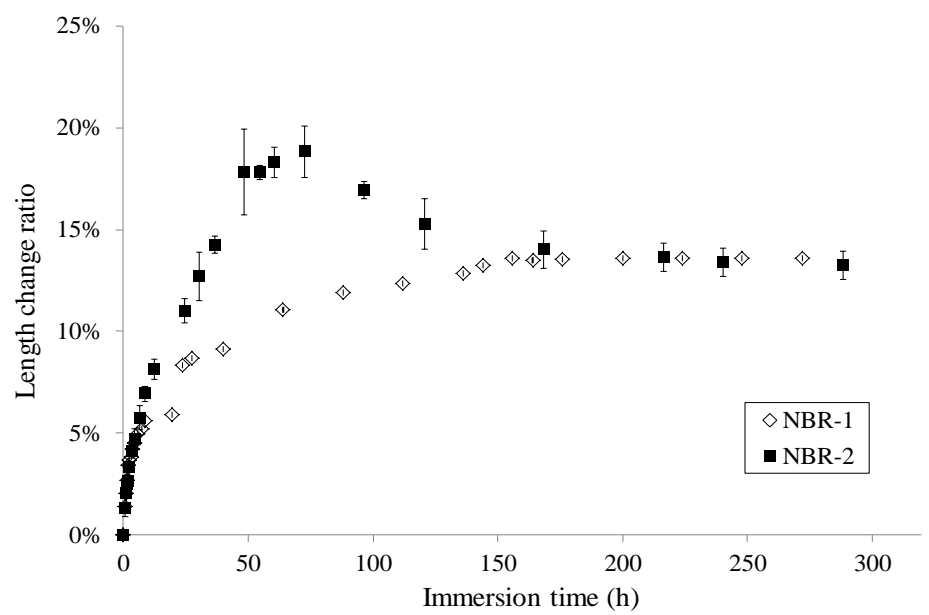

Figure 4. Comparison in the length change ratio for NBR-1 and NBR-2 in MilliQ water.

\section{Conclusion}

This work presents the first report on the experimental evaluation of the effectiveness of nitrile protective gloves against gold nanoparticles in solution and under simulated working conditions. The results obtained are different depending on the size of the $\mathrm{nAu}$ ( 5 or $50 \mathrm{~nm}$ ) and also depending on the batch of gloves. Indeed, in contrast to $\mathrm{nAu}-50, \mathrm{nAu}-5$ seems to penetrate nitrile rubber gloves after 3 hours of mechanical deformations. But when the gloves are taken from a second box (different batch), no penetration is observed for both $\mathrm{nAu}$.

These results highlight two main challenges linked with this type of study. The first is to understand the external parameters that can influence the penetration of nanoparticles through protective gloves. The second is to consider the irreproducibility of the chemical composition of the protective gloves. This chemical composition is not yet well controlled in the manufacturing process.

To conclude, the authors still perceive from the results in this paper much uncertainty about the effectiveness of protective gloves against nanoparticles in aqueous solutions and deem that further investigation is needed.

\section{Future work}

Several additional projects are currently underway to better understand the potential transfer of nanoparticles through laboratory gloves. Studies are being conducted on the swelling of glove material in colloidal and saline solutions. Tests are also being performed to evaluate the integrity of protective gloves when submitted to mechanical deformations (surface features, degree of crosslinking and crystallization). Also, further understanding as to the effect of the size and shape of the nanoparticles will be sought.

\section{Acknowledgments}

This research was supported by the Institut Robert-Sauvé de recherche en santé et sécurité du travail (IRSST). The authors acknowledge the technical contributions of Mehdi Ben Salah and Nidal Boutrigue (École de technologie supérieure) and Madjid Hadioui (Université de Montréal).

\section{References}

[1] A. M. Alkilany and C. J. Murphy, "Toxicity and cellular uptake of gold nanoparticles: what we have learned so far?," J Nanopart Res., vol. 12, no. 7, p. 2313-2333, 2010.

[2] S. K. Balasubramanian, L. Yang, L.-Y. L. Yung, C.-N. Ong, W.-Y. Ong and L. E. Yu, "Characterization, purification, and stability of gold nanoparticles," Biomaterials, vol. 31, no. 34, p. 9023-9030, 2010.

[3] F. Bueche, "Molecular basis for the mullins effect," Applied Polymer, vol. 4, no. 10, p. 107-114, 1960.

[4] S. Das, N. Debnath, S. Mitra, A. Datta and A. Goswami, "Comparative analysis of stability and toxicity profile of three differently capped gold nanoparticles for biomedical usage," Biomaterials, vol. 25, no. 5, pp. 1009-1022, 2012.

[5] L. Dykman and N. Khlebtsov, "Gold nanoparticles in biomedical applications: recent advances and perspectives," Chemical Society Reviews, vol. 41, no. 6, pp. 2256-2282, 2012.

[6] E.C.F., "Reference test method for release of nickel from product intended to come in direct and prolonged contact with the skin," BS EN 1811:1998+A1:2008, Brussels CEN, 1998.

[7] C. Fede, I. Fortunati, V. Weber, N. Rossetto, F. Bertasi, L. Petrelli, D. Guidolin, R. Signorini, R. De Caro, G. Albertin and C. Ferrante, "Evaluation of gold nanoparticles toxicity towards human endothelial cells under static and flow conditions," Microvascular Research, vol. 97, pp. 147-155, 2015. 
[8] L. Golanski, A. Guiot, F. Rouillon, J. Pocachard and F. Tardif, "Experimental evaluation of personal protection devices against graphite nanoaerosols: fibrous filter media, masks, protective clothing, and gloves," Human and Experimental Toxicology, vol. 28, no. 6-7, pp. 353-359, 2009.

[9] L. Golanski, A. Guiot and F. Tardif, "Are conventional protective devices such as fibrous filter media, respirator cartridges, protective clothing and gloves also efficient for nanoaerosols?," Europian Strategy for Nanosafety, Cedex, France, 2008.

[10] C. M. Goodman, C. D. McCusker, T. Yilmaz and V. M. Rotello, "Toxicity of gold nanoparticles functionalized with cationic and anionic side chains," Bioconjug Chem., vol. 15, no. 4, pp. 897900, 2004.

[11] C. Graf, D. Nordmeyer, S. Ahlberg and E. Rühl, "Penetration of spherical and rod-like gold nanoparticles into intact and barrier-disrupted human skin," in Colloidal Nanoparticles for Biomedical Applications X, At San Francisco, 2015.

[12] B. Gulson, M. McCall, M. Korsch, L. Gomez, P. Casey, Y. Oytam, A. Taylor, M. McCulloch, J. Trotter, L. Kinsley and G. Greenoak, "Small amounts of zinc from zinc oxide particles in sunscreens applied outdoors are absorbed through human skin," Toxicol Sci., vol. 118, no. 1, pp. 140-149, 2010.

[13] S. Guo and E. Wang, "Synthesis and electrochemical applications of gold nanoparticles," Analytica Chimica Acta, vol. 598, no. 2, p. 181-192, 2007.

[14] K. S. Lokesh, A. Shambhulinga, N. Manjunatha, M. Imadadulla and M. Hojamberdiev, "Porphyrin macrocycle-stabilized gold and silver nanoparticles and their application in catalysis of hydrogen peroxide," Dyes and Pigments, vol. 120, p. 155-160, 2015.

[15] J. Marchal, Cristallisation des caoutchoucs chargés et non chargés sous contrainte: Effet sur les chaines amorphes, Paris: XI Orsay, 2006.

[16] J. Park, B. K. Kwak, Y. Kim and J. Yi, "Efficiency of protective dermal equipment against silver nanoparticles with water aerosol," Journal of Nanoparticle Research, vol. 13, no. 7, pp. 30433049, 2011.

[17] G. Perron, J. E. Desnoyers and J. Lara, "Résistance des vêtements de protection aux mélanges de solvants industriels - Développement d'un outil de sélection," Prévention des risques mécaniques et physiques, France, 2002.
[18] J. G. Rouse, J. Yang, J. P. Ryman-Rasmussen, A. R. Barron and N. A. Monteiro-Riviere, "Effects of Mechanical Flexion on the Penetration of Fullerene Amino Acid-Derivatized Peptide Nanoparticles through Skin," Nano Letters, vol. 7, no. 1, p. 155160, 2007.

[19] J. P. Ryman-Rasmussen, J. E. Riviere and N. A. Monteiro-Riviere, "Penetration of intact skin by quantum dots with diverse physicochemical properties," Toxicological Sciences, vol. 91, no. 1, pp. 159-165, 2006.

[20]C. R. Cozart, A. K. Patri, S. E. McNeil, P. C. Howard, W. H. Doub and L. F. Buhse, "Lack of Significant Dermal Penetration of Titanium Dioxide from Sunscreen Formulations Containing Nano- and Submicron-Size $\mathrm{TiO}_{2} \quad$ Particles," Toxicological Sciences, vol. 115, no. 1, pp. 156-166, 2010.

[21] P. M. Tiwari, K. Vig, V. A. Dennis and S. R. Singh, "Functionalized Gold Nanoparticles and Their Biomedical Applications," Nanomaterials, vol. 1, no. 1, pp. 31-63, 2011.

[22] L. Vinches, Y. Boulebrane, G. Perron and K. J. Wilkinson, "Swelling of Protective Gloves in Commercial TiO2 Nanoparticles Colloidal Solutions," International Journal of Theoretical and Applied Nanotechnology (IJTAN), vol. 1, no. 1, pp. 45-51, 2011.

[23] L. Vinches, J. d. S. Barbara, S. Hallé, P. Dolez and K. J. Wilkinson, "Physical Phenomena Facilitating the Penetration of Solutions of $\mathrm{TiO} 2$ Nanoparticles through Protective Gloves," International Journal of Theoretical and Applied Nanotechnology (IJTAN), vol. 1, no. 2, pp. 1-16, 2013.

[24] L. Vinches, P. Dolez, K. J. Wilkinson and S. Hallé, "Experimental evaluation of the resistance of nitrile rubber protective gloves against $\mathrm{TiO} 2$ nanoparticles in water under conditions simulating occupational use," Journal of Physics: Conference Series, vol. 429, no. 1, 2013.

[25] L. Vinches, G. Perron, P. Dolez, K. J. Wilkinson and H. Stéphane, "Swelling of Elastomers in Solutions of TiO2 Nanoparticles," International Scholarly Research Network - Polymer Science, vol. 2012, pp. 1-8, 2012.

[26] L. Vinches, S. Hallé, C. Peyrot and K. J. Wilkinson, "Which Gloves Are Efficient To Protect Against Titanium Dioxide Nanoparticles In Work Conditions?," International Journal of Theoretical and Applied Nanotechnology (IJTAN), vol. 2, pp. 2429, 2014. 
[27] A. Vogt, F. Rancan, S. Ahlberg, B. Nazemi, C. S. Choe, M. E. Darvin, S. Hadam, U. Blume-Peytavi, K. Loza, J. Diendorf, M. Epple, C. Graf, E. Rühl, M. C. Meinke and J. Lademann, "Interaction of dermatologically relevant nanoparticles with skin cells and skin," Beilstein J. Nanotechnology, vol. 5, pp. 2363-2373, 2014.

[28] V. Wiwanitkit, A. Sereemaspun and R. Rojanathanes, "Effect of gold nanoparticles on spermatozoa: the first world report," Fertility and Sterility, vol. 91, no. 1, pp. e7-e8, 2009.

[29] S. T. Zakhidov, S. M. Pavlyuchenkova, T. L. Marshak, M. V. Rudoy, O. V. Dement'eva, I. A. Zelenina, S. G. Skuridin, A. A. Makarov, A. N. Khokhlov and Y. M. Evdokimov, "Effect of gold nanoparticles on mouse spermatogenesis," Biology Bulletin, vol. 39, no. 3, pp. 229-236, 2012.

[30] P. Zhao, N. Li and D. Astruc, "State of the art in gold nanoparticle synthesis," Coordination Chemistry Reviews, vol. 257, no. 3-4, p. 638-665, 2013.

[31] Y. Zhu, C. S. Choe, S. Ahlberg, M. C. Meinke, U. Alexiev, J. Lademann and M. E. Darvin, "Penetration of silver nanoparticles into porcine skin ex vivo using fluorescence lifetime imaging microscopy, Raman microscopy, and surface-enhanced Raman scattering microscopy," Journal of Biomedical Optics, vol. 20, no. 5, pp. 1-8, 2015. 